\title{
OVERVIEW OF ENERGY GRID IN INDIA
}

\author{
Avani Pujara $^{1}$, Neel Chikhal ${ }^{2}$, Kaushal Singh ${ }^{3}$ \\ 1, 2, ${ }^{3}$ Keystone School of Engineering Pune
}

\begin{abstract}
Economical growth in India has led to considerable growth in power sector. This paper presents the overview of grid energy in India. Load dispatch centers and their roles in the management of electrical power transmission have been discussed thoroughly. Also this paper glides us through recent HVDC projects in India.
\end{abstract}

Keywords- Load Dispatch Centers, National Grid, HVDC, Challenges in the grid management, 'One Nation One Grid One Frequency'

\section{INTRODUCTION}

Electricity is the most important infrastructural input in the development of economy. For smooth evacuation of power from generating stations to consumers, transmission and grid management are essential functions.

Grid management refers ensured moment to moment power balance in the interconnected system, whereas transmission refers to the maintenance of transmission infrastructure.

Earlier the country was divided geographically into five regions namely northern, western, eastern, northeastern and southern. The first four out of these five regional grids operated in synchronous mode which meant power in these regions can flow seamlessly as per relative load generation balance. The southern grid was connected to the rest of Indian grid through asynchronous links which meant quantum and direction of power flow could be controlled manually [2].

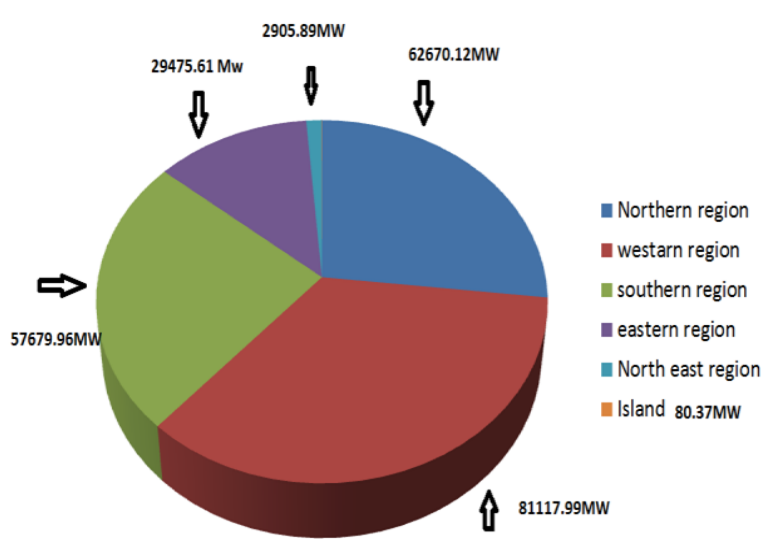

Fig 1: pie chart showing power pproduction in different regions.
Figure 1 shows power produced in different regions of India.

The western region of India dominates the charts by producing $81,117 \mathrm{MW}$ of power [2].

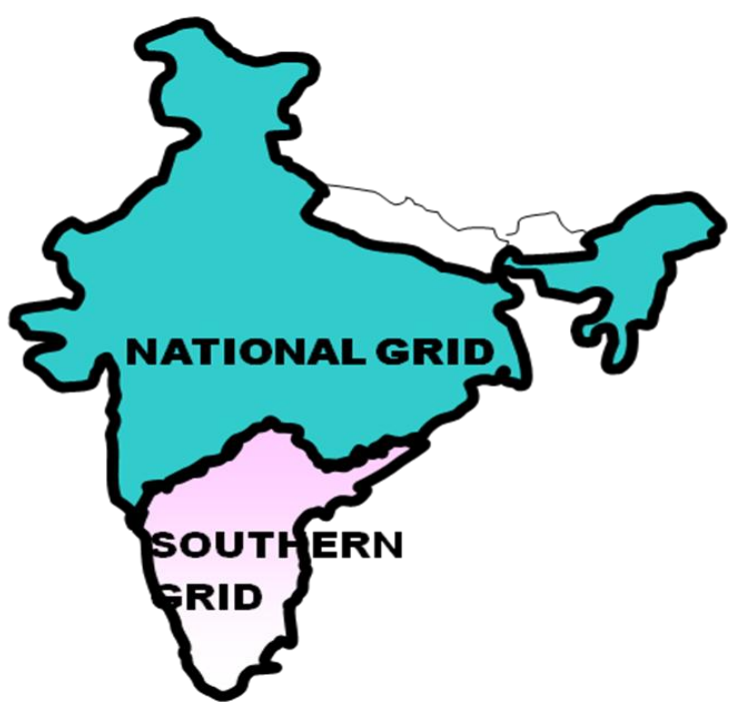

Fig 2: Electrical grids of India

Figure 2 describes that India, is currently divided between two grids namely, national and southern. All the grids in India are being run by state owned POWERGRID Corporation.

- Transmission lines run all over India forming a circuit network of 1, 04,200 km.

- The power transformation capacity is about

- $1,85,638 \mathrm{MVA}$.

- The numbers of substations managing the network are 176.

The total inter-regional power transfer capacity is $33,950 \mathrm{MW}$ [1]. 


\section{GRID EVOLUTION}

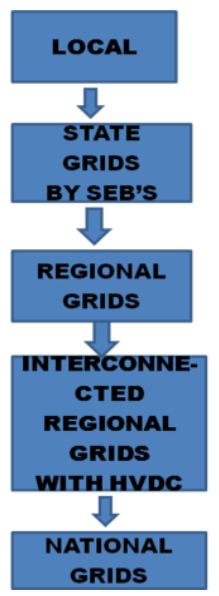

Fig3: Grid Evolution

The above figure shows grid evolution from 1950 onwards.

- Pre-independence-Small Isolated System

- During 60s-limited interconnection between neighboring states.

- Late 80s-Integrated grid operation through $400 \mathrm{kV}$ system.

- Late 90s-Asynchronous inter-regional links.

\section{LOAD DISPATCH CENTRE (LDC)}

The control of grid is planned to be done at three levels of hierarchy namely, National Load Dispatch Centre (NLDC), Regional Load Dispatch Centre (RLDC) and State Load Dispatch Center (SLDC).

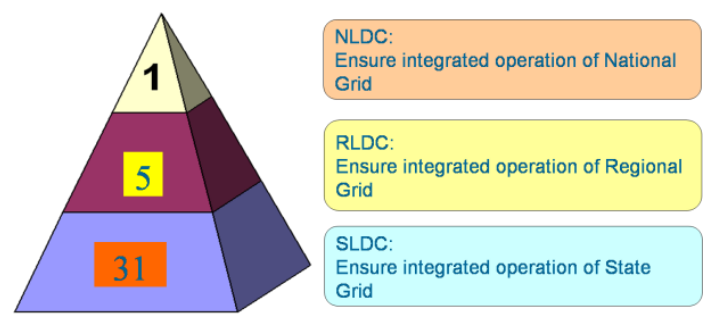

Fig 4: Grid Management Heirarchy

As per Electricity Act (EA) 2003, LDC's monitor grid operations, exercise supervision and control over the interstate transmission system and are responsible for optimum scheduling and dispatch of electricity within the region.

Presently POWERGRID is operating a National Power system Desk (NPSD) for information exchange and facilitating interregional transactions'.

- RLDC is responsible for carrying out real time operations of the grid control and dispatch electricity within a region through secure operations of regional grid.
- The functions of SLDC elaborated in EA 2003 are similar to that of RLDC except the area of jurisdiction which in case of SLDC is the state [1].

\section{NATIONAL GRID}

- National grid was set up in late 90s.The National Grid is basically combination of eastern, western, northern and northeastern regional grids.

- The National Grid was set up with idea that it would help in electrical power transfer from surplus regions to deficit regions.

- Also it focuses on maximum utilization of resources from diversified regions.

- National Grid coordinates with RLDC for energy accounting for inter-regional exchange of power.

\section{OPERATING AIDS FOR GRID MANAGEMENT}

- In order to enhance the power system visibility and improve the quality of supervision in real time operation. In the country, the grid control rooms at regional and state levels have been equipped with a State-of-the-art communication and data acquisition systems.

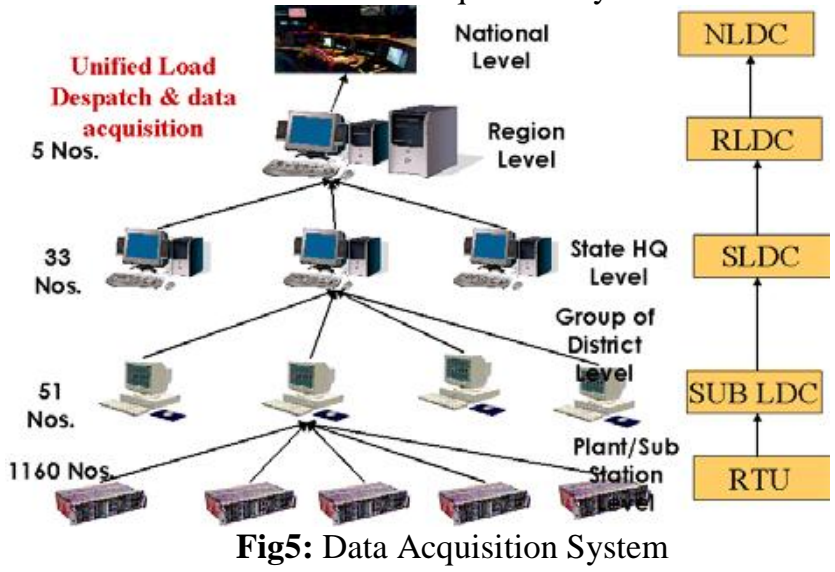

- The above figure explains a typical data acquisition system for electrical communication.

- Under the system the vital system variables are measured with the help of transducers installed at all the important locations.

\section{HVDC}

- Introduction to High Voltage Direct Current has revolutionalised the existing power systems.

- In the second era of electricity revolution alternating current (AC) displaced direct current (DC) because its voltage can be stepped up and lower currents that results can be pumped through relatively thinner wires.

- HVDC comes into play when large volumes of electricity need to be transmitted over distances above $800 \mathrm{~km} \mathrm{[3].}$ 
Table 1: HVDC projects in India

\begin{tabular}{|l|l|l|l|l|l|l|}
\hline Sr.No. & $\begin{array}{l}\text { Project } \\
\text { name }\end{array}$ & $\begin{array}{l}\text { Commissioned } \\
\text { on }\end{array}$ & $\begin{array}{l}\text { Power } \\
\text { Rating } \\
(\mathrm{MW})\end{array}$ & $\begin{array}{l}\text { AC } \\
\text { Voltage } \\
(\mathrm{kV})\end{array}$ & $\begin{array}{l}\text { DC } \\
\text { Voltage } \\
(\mathrm{kV})\end{array}$ & $\begin{array}{l}\text { Length } \\
\text { Of } \\
\text { Line } \\
(\mathrm{km})\end{array}$ \\
\hline 1 & $\begin{array}{l}\text { Rihand } \\
\text {-Dadri }\end{array}$ & Dec-1991 & 1500 & 400 & 500 & 816 \\
\hline 2 & $\begin{array}{l}\text { Talcher- } \\
\text { Kolar }\end{array}$ & Jun-2003 & 2000 & 400 & 500 & 1369 \\
\hline 3 & $\begin{array}{l}\text { Mundra- } \\
\text { Mohindergar }\end{array}$ & 2012 & 1500 & 400 & 500 & 986 \\
\hline 5 & Ballia-Bhiwadi & $\begin{array}{l}\text { Pole1-Mar2010 } \\
\text { Pole2- } \\
\text { Mar-2011 }\end{array}$ & 2500 & 400 & 500 & 780 \\
\hline 5 & Biswanath-Agra & 2015 & 6000 & 400 & 800 & 1728 \\
\hline
\end{tabular}

\section{BACK TO BACK HVDC PROJECTS}

Back to Back stations are those stations where both the convertors are housed in the same building and the length of the $\mathrm{dc}$ line is kept as short as possible.

It has the advantage of bidirectional power flow.

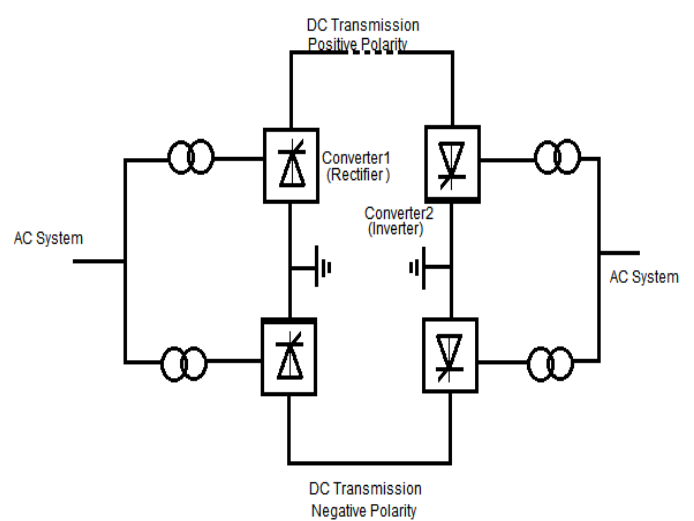

Fig 6: Back to Back HVDC Links

Currently there are 4 Back to Back Projects in India namely:

- Vindhyachal

- Sasaram

- Chandrapur

- Gazuwaka[4].

\section{CASE STUDY: ONE NATION, ONE FREQUENCY, ONE GRID}

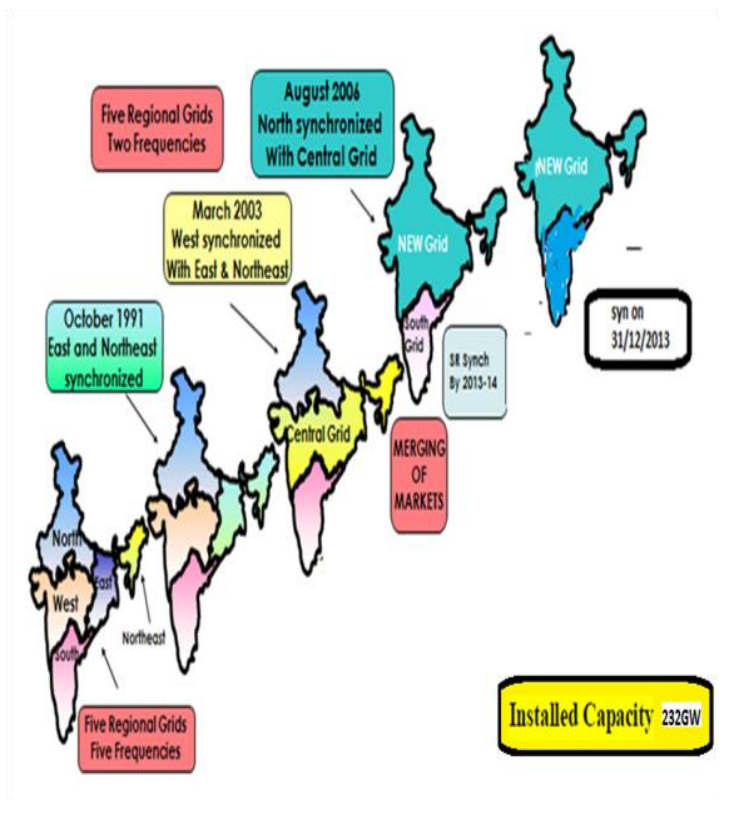

Fig7: Synchronization of Indian grids

- The central transmission utility POWERGRID successfully commissioned the Raichur-Solapur $765 \mathrm{kV}$ single circuit transmission line on Jan 2014.

- This transmission line interconnects southern grid, synchronously with rest of the Indian grids.

- It cost the POWERGRID CORPORATION 815crores to set up the system.

- The power generation capacity is $232 \mathrm{GW}$.

- With this India became one of the largest operating synchronous grids in the world.

- With this project power deficit southern states especially Andhrapradesh, Tamilnadu and Kerala are able to utilize the power from surplus regions. 
Table 2: All India Power Supply Position

\begin{tabular}{|l|l|l|l|l|}
\hline \multirow{2}{*}{ Region } & Power & \multicolumn{3}{|l|}{} \\
\cline { 2 - 5 } & Requirement & Availability & $\begin{array}{l}\text { Surplus(+) } \\
\text { /Deficit(-) }\end{array}$ & \multirow{2}{*}{ (\%) } \\
\cline { 2 - 5 } & $(\mathrm{MU})$ & (MU) & (MU) & \\
\hline Northern & 319885 & 301418 & -18467 & -5.8 \\
\hline Western & 286752 & 283396 & -3356 & -1.2 \\
\hline Southern & 309840 & 250583 & -59257 & -19.1 \\
\hline Eastern & 119632 & 131880 & 12248 & 10.2 \\
\hline Northeastern & 12424 & 11024 & -1400 & -11.3 \\
\hline All India & 1048533 & 978301 & -70232 & 6.7 \\
\hline
\end{tabular}

- The south witnessed peak power deficit of $6.8 \%$ in Nov 2013 according to the latest official data from POWERGRID.

- Peak power deficit refers to the shortage of electricity when the demand is at maximum.

- In last November, while the southern regions electricity demands reached $34,118 \mathrm{MW}$ the availability was only $31,786 \mathrm{MW}$.

- With the introduction of One Nation, One Grid, One Frequency the supply demand situation improved.

Table: 3 Frequency Profile of northern, western, eastern, northeastern and southern regions in the year 2013

\begin{tabular}{|c|l|l|l|l|}
\hline \multirow{3}{*}{ Month } & \multicolumn{4}{l|}{ Frequency Profile } \\
\cline { 2 - 5 } & NR/WR/ER/NER & \multicolumn{2}{l|}{ SR } \\
\cline { 2 - 5 } & Max.Freq. & Min. Freq & Max.Freq. & Min. Freq \\
\hline Aug'2013 & 50.77 & 49.65 & 50.62 & 49.01 \\
\hline Sep'2013 & 50.62 & 49.21 & 50.61 & 49.21 \\
\hline Oct'2013 & 50.63 & 49.28 & 50.53 & 49.20 \\
\hline Nov'2013 & 50.51 & 49.48 & 50.61 & 49.24 \\
\hline Dec'2013 & 50.69 & 49.33 & 50.73 & 49.44 \\
\hline
\end{tabular}

- On December 2013 One Nation One Grid One Frequency mission was incorporated.

- Table: 3 give an idea about frequency matching between southern region and with the rest of the Indian grid [5].

\section{CHALLENGES IN GRID MANAGEMENT}

- Large interconnected grids are essential for reliability of power supply and for exploitation spatially distributed energy resources centers in the country.

- The manifold growth in the network size has increased the complexity of the grid management.

- The physical nature of power flow on transmission lines, rapidly changing demand patterns, dramatic changes in the system pattern makes grid management extremely challenging.
- Competition has heightened the market pressure, forcing system to be operated closer to its physical limits.

- The conflict of interests, unclear responsibilities, inadequacy of resources and legacy issues among these utilities often impair collective performance of grid management.

- All the above coupled with rapidly diminishing species of power system engineers and general lack of appreciation of this vital function is making grid management a tough job.

\section{CONCLUSIONS}

- The overview of Indian grid is described giving detailed explanations about the various load dispatch centers.

- The evolution of grid from prior to independence to late 90's was studied.

- The concept of HVDC is explained in this paper and recent projects commissioned regarding HVDC are mentioned.

- Finally, One Nation One Grid One Frequency mission accomplished on $31^{\text {st }}$ December 2013 same is described as case study along with its advantages.

- With the development and resources over time more and more projects have been introduced and efficient power transmission is carried out which earlier was not possible to such an extent.

\section{REFERENCES}

[1]. http://www.powergridindia.com

[2]. http://www.cea.nic.in/

[3]. 'An Overview to HVDC links in India'

International Journal of Electrical, Electronics ISSN No. 2277-

2626 and Computer Engineering 2(1): 94-98(2013)

[4]. 'HVDC transmission in India'

Potentials, IEEE (Volume: 33, Issue:1)ISSN No.0278-6648

[5]. http://www.mahatransco.in/ 